\title{
Processo de enfermagem e sistematização da assistência de enfermagem - intenção de uso por
} profissionais de enfermagem

Emilia Campos de Carvalho', Maria Márcia Bachion"

1 Professora Titular da Escola de Enfermagem de Ribeirão Preto da Universidade de São Paulo. Pesquisadora CNPQ. E-mail: ecdcava@eerp.usp.br.

"Professora Titular da Faculdade de Enfermagem da Universidade Federal de Goiás. E-mail: mbachion@gmail.com.

A Enfermagem tem se voltado para a revisão de termos empregados na prática profissional, bem como o seu significado e uso. Entre eles, estão "sistematização da assistência de enfermagem" e "processo de enfermagem".

Sistematização pressupõe a organização em um sistema, que por sua vez implica em um conjunto de elementos, dinamicamente inter-relacionados. Estes elementos podem ser compreendidos, no caso da sistematização da assistência, por um conjunto de ações, uma seqüência de passos, para alcance de um determinado fim.

Existem diversos modos de sistematizar a assistência de enfermagem, entre as quais podemos citar os planos de cuidados, os protocolos, a padronização de procedimentos e o processo de enfermagem. Trata-se de diferentes formas de se desenvolver a assistência, ou seja, diversos métodos podem ser utilizados para se solucionar uma dada situação, em um dado contexto, em um determinado tempo, com a finalidade de produzir resultados positivos para a saúde das pessoas que cuidamos. Estas modalidades de agir não são excludentes e têm naturezas distintas.

O processo de enfermagem envolve uma seqüência de etapas específicas (obtenção de informações multidimensionais sobre o estado de saúde, identificação das condições que requerem intervenções de enfermagem, planejamento das intervenções necessárias, implementação e avaliação das ações), com a finalidade de prestar atendimento profissional ao cliente, seja ele indivíduo, família ou comunidade, de forma a considerar suas singularidades e de modo ampliado. Requer bases teóricas do campo da Enfermagem e de fora dela. Podemos dizer que se trata da expressão do método clínico na nossa profissão.

As diferentes formas de sistematização da assistência pressupõem a organização das condições, dos recursos materiais e humanos além da competência técnico-legal e valorização dada à sua contribuição, seja pela instituição, seja pelo profissional.

Dentre esses aspectos, destacamos a predisposição ou intenção de uso desses métodos. Do ponto de vista dos modelos motivacionais ${ }^{(1)}$, o comportamento é função da intenção de agir e da percepção de controle sobre o comportamento; por sua vez a intenção de agir é determinada pela atitude relacionada ao comportamento (avaliações que o indivíduo faz em face dos resultados prováveis ou esperados), a norma subjetiva (pressão social percebida pela realização ou não do comportamento), e o controle comportamental percebido (percepções pessoais sobre sua capacidade para o desempenho do comportamento).

Cada um desses componentes tem um valor distinto segundo o comportamento em análise, situação ou grupo de pessoas. Tais elementos tem se mostrado efetivos para predizer a intenção de um dado comportamento. Ainda, deve se considerar, além da motivação para o comportamento, a implementação do comportamento, isto é a ação ou tarefa, a partir de seu planejamento, que contempla as respostas a quando, como e onde agir; pessoas que formulam tal planejamento apresentam maiores chances de agir conforme pretendido $^{(2)}$.

Assim, podemos apontar iniciativas bem sucedidas de pessoas e instituições que buscam criar condições para utilizar os métodos de organizar a assistência de enfermagem ${ }^{(3)}$, não como um fim em si mesmo, mas como meios para alcançar a maior de nossas finalidades: prestar atendimento digno, sensível, competente e resolutivo, de modo a contribuir para a melhoria da situação de saúde da população.

\section{REFERÊNCI AS}

1. Ajzen I. Theory of planned behavior. Organ Behav Hum Decis Process 1991; 50(2):179-211.

2.Orbell S, Sheeran P. Motivational and volitional processes in action initiation: a field study of the role of implementation intentions. J Appl Soc Psychol 2000; 30(4): 780-97.

3. Anais do III Simpósio Internacional - Processo de Enfermagem: verdades e desafios. Bauru. 26-28. Agosto 2009. Instituto Lauro de Sousa Lima. 